\title{
Immunopathology of schistosomiasis
}

\author{
Mark S Wilson, Margaret M Mentink-Kane, John T Pesce, Thirumalai R Ramalingam, Robert \\ Thompson, and Thomas A Wynn \\ Laboratory of Parasitic Diseases, Immunopathogenesis Section, National Institute of Allergy and \\ Infectious Diseases, National Institutes of Health, Bethesda, MD, USA
}

\section{Abstract}

Waterborne parasitic diseases plague tropical regions of the world with the development of water resources often increasing transmission. Skin-penetrating cercariae (infectious stages of schistosome parasites) mature within their mammalian host, form sexual pairs and produce several hundred eggs per day. Many eggs are swept within the circulation and in the case of Schistosoma mansoni and $S$. japonicum, become lodged within hepatic sinusoids, invoking a fibrotic granulomatous response. Animal studies have identified a moderate type 1 helper (Th1) response to parasite antigens; however, a robust Th2 response to egg-derived antigens dominates and propagates fibrogenesis within the liver. Elegant $\mathrm{T}$ helper cell polarization studies have highlighted that critical control of Th1, Th2 and interleukin (IL)-17-secreting lymphocytes is necessary to prevent severe liver pathology. Alternatively activated macrophages develop in the Th2 milieu and upregulate Fizz1, Ym-1 and Arg-1. The possible contribution of macrophages to fibrogenesis and their role in immune regulation are discussed. Within the liver, natural $\left(\mathrm{CD} 4^{+} \mathrm{CD} 25^{+}\right.$Forkhead box protein $\left.3(\text { Foxp3 })^{+}\right)$and inducible $\left(\mathrm{CD} 4^{+}\right.$Foxp3 $\left.3^{-}\right)$Treg's are recruited, providing an essential regulatory arm to stabilize the immune response and limit immunopathology. This review ties together current thinking of how the granulomatous response develops, causing much of the associated immunopathology, with extensive discussions on how regulatory cells and cytokine decoy receptors serve to limit the extent of immune-mediated pathology during schistosomiasis.

\section{Keywords}

schistosomiasis; inflammation; pathology; immune regulation; Treg; decoy receptor

\section{‘THE GOOD AND THE BAD’ FEATURES OF GRANULOMAS}

Of the 19 species of Schistosoma, some are predominantly human parasites (Schistosoma mansoni and $S$. haematobium), some are zoonoses, infecting man, wild animals and domestic stock (e.g. S. japonicum) and some are primarily veterinary pathogens (S. bovis and $S$. curassoni). As mice are highly susceptible and the parasites are relatively easy to maintain in the lab, the host immune response to $S$. mansoni infection has been the most widely studied of the major schistosome species. Upon infection, adult parasites of $S$. mansoni migrate to the mesenteric veins where they live up to 10 years or more, laying hundreds of eggs per day. Some of the eggs are trapped in the microvasculature of the liver and once there, they induce a vigorous granulomatous response. ${ }^{1}$ Subsequently, fibrosis, portal hypertension and collateral vessels may develop, which are the primary causes of 
morbidity in infected individuals and in some cases will ultimately be lethal. Consequently, much of the symptomatology of schistosomiasis is attributed to the egg-induced granulomatous inflammatory response and associated fibrosis. ${ }^{2}$

Although egg-induced granulomas are detrimental to the infected host, it is clear that the lesions also serve an important host-protective function, particularly during $S$. mansoni infection. ${ }^{1}$ Schistosome eggs and their secreted products provide a continuous antigenic stimulus for the immune response. If these antigens are not sequestered or neutralized effectively, they can damage the affected tissues, with hepatocytes being particularly sensitive to toxins secreted by the eggs. ${ }^{3}$ Indeed, T-cell-deprived, nude, severe combined immunodeficiency disease or egg-tolerized mice all die earlier than comparably infected immunologically intact mice because they are unable to mount a protective granulomatous response. Widespread hepatic damage induced by toxic egg products contributes to the decreased survival of infected immunocompromised mice. Granuloma formation therefore seems to be a compromise, which allows the host to live with the infection for many years. Presumably, the chronic detrimental effects associated with granulomas (fibrosis, portal hypertension) represents a better alternative, for host and parasite, than that of the host dying soon after parasite egg production.

\section{HUMAN SCHISTOSOMIASIS}

Alarming statistics of the global burden of Schistosomiasis, presented by the WHO in $1973^{4}$, estimated 600 million people at risk of infection with 200 million infected.

Unfortunately, recent estimates suggest 700 million at risk with almost 200 million infected in Africa alone, ${ }^{5}$ despite effective and inexpensive chemotherapy. 6,7

Schistosomes cause varying clinical symptoms and organ complications due to the specific tropisms of different species. For example, $S$. mansoni resides in the mesenteric veins of the intestinal tract with disease symptoms including anemia, malnourishment and stunted growth, progressive liver fibrosis, portal hypertension and hematemesis in later life. $S$. haematobium, however, resides in vessels of the bladder causing urinary schistosomiasis manifested by hematuria, bladder calcification, kidney damage and increased risk of bladder cancer. The immunology of schistosomiasis has progressed through the use of murine and non-human primate animal models, corroborating in many cases with human data. ${ }^{8}$ This review will focus primarily on murine models of schistosomiasis, which have helped clarify the pathological consequences that results from dysregulated immune responses. For a detailed analysis of human immunology to schistosomiasis see several recent comprehensive reviews by Dessein et al. ${ }^{8}$, Secor ${ }^{9}$, Vennervald and Dunne ${ }^{10}$ and Abath et al. ${ }^{11}$

\section{ORIGINS OF IMMUNOPATHOLOGY: CD4+ T HELPER CELLS}

Chronic morbidity during infection with $S$. mansoni develops as a result of schistosome eggs that lodge in the liver, gut and other organs causing extensive tissue damage. An immunocompetent host mounts a vast immunological rebuttal to parasite eggs with the development of a vigorous collagen-rich granulomatous response around the eggs. This response eventually sequesters egg products but can also lead to severe hepatic fibrosis and portal hypertension.

It has long been appreciated that immune competency is necessary for effective granulomatous reactions to develop. T-cell-deficient mice, in particular CD4 helper T-celldeficient mice fail to mount an effective granulomatous response. ${ }^{12-14}$ In immunocompetent wild-type (Wt) mice, immune responses to schistosome antigens manifest a striking shift from a moderate Th1 to a robust Th2-dominated response with the onset of egg laying around 5-6 weeks. ${ }^{1}$ Whereas the relative contribution of interferon (IFN)- $\gamma$-producing Th1 
cells and IL-4, IL-5 and IL-13 producing Th2 cells in the granulomatous response has long been debated, fibrosis and much of the pathology is primarily mediated by Th2 cytokines ${ }^{15,16}$ and not by transforming growth factor (TGF)- $\beta .{ }^{17}$ Vaccination of mice with parasite eggs and IL-12 (a potent Th1 inducing cytokine) inhibits the Th1 to Th2 shift and results in amelioration of hepatosplenic pathology following infection, ${ }^{18}$ suggesting that a chronic Th2 response may be detrimental. Studies addressing the role of Th2 responses using mice deficient in IL-4Ra ${ }^{19}$ or its downstream signaling molecule signal transducer and activator of transcription (STAT) $6^{20}$ confirmed that the IL-4/IL-1-mediated STAT6 pathway plays a critical role in the development of the granulomatous response and resulting fibrosis observed in schistosomiasis. However, mice deficient in IFN- $\gamma$ signaling also display a reduction in granuloma size and seem to transition into the chronic phase of the response more rapidly, ${ }^{21}$ suggesting that IFN- $\gamma$ also contributes to granuloma formation. Whereas IFN- $\gamma$ has been shown to have strong antifibrotic activities in other experimental models, ${ }^{22}$ excessive IFN- $\gamma$ can also cause severe liver pathology in schistosomiasis. ${ }^{23}$ Thus, extreme immune polarization towards either Th1 or Th2 during schistosomiasis is in fact detrimental if not lethal and any attempts to implement an immune deviation strategy should be executed with caution. This was illustrated by seminal studies with mice that lack both IL-10 and IL-4, which upon schistosome infection, develop an unchecked Th1 response and manifest $100 \%$ mortality by 9 weeks post-infection. Similarly, mice lacking IL-10 and IL-12 develop a vigorous Th2 response that is detrimental during the chronic phase of infection and display significant mortality by $12-15$ weeks post-infection. ${ }^{23}$ If this model is applicable to other Th2-dominated diseases, such as allergy and asthma, then similar precaution must be taken. Importantly, maintaining a balanced and controlled Th1 or Th2 response is critical - in the case of schistosomiasis for protective granuloma formation without excessive pathology.

Recent studies have uncovered a potentially new T-cell lineage characterized by IL-17 secretion. ${ }^{24,25}$ Similar to the Th1-Th2 paradigm, antagonism extends to IL-17-secreting cells, with both IFN- $\gamma^{26}$ and IL- $4{ }^{27}$ suppressing their development. Given the elevated levels of both IFN- $\gamma$ and IL-4 at different times during infection with $S$. mansoni, IL-17 production is likely tightly controlled, with a role during schistosome infection only recently suggested. Similar to IL-10/IL-4 double knockout (KO) mice, which polarize towards a Th1 response, immunization with soluble egg antigens (SEA) in complete Freunds adjuvant (CFA) also skews the T-cell response in the Th1 direction following infection, resulting in increased inflammation and larger granulomas, extensive pathology and accelerated mortality. ${ }^{28}$ This immunization protocol, however, also revealed a role for IL-17 in $S$. mansoni induced pathology, with severe morbidity correlating with high levels of IL-17. Furthermore, CBA mice display a vigorous IL-17 response following infection with $S$. mansoni, leading to severe liver pathology. Neutralization with anti-IL-17 mAb restored granuloma size in CBA mice to that of control mice, ${ }^{29}$ supporting the notion that 17secreting cells play an inflammatory role during acute $S$. mansoni infection if left unregulated.

In humans, the regulation of liver fibrosis during schistosomiasis may be even more complex with multiple mediators regulating the progression of disease. Patients presenting with severe fibrosis have been associated with elevated tumor necrosis factor (TNF)- $a, 30,31$ IL-5, IL-10 $0^{32}$ and IL-13, ${ }^{33}$ whereas low fibrosis patients present high levels of IFN- $\gamma .{ }^{30}$ These data corroborate the current hypothesis from animal studies that Th2 cytokines like IL-13 are responsible for the majority of immunopathology and fibrosis during infection. 


\section{MACROPHAGES AND FIBROSIS}

Macrophages (MФ), similar to Th1 and $\mathrm{Th} 2 \mathrm{CD}^{+}{ }^{+} \mathrm{T}$ cells, can be polarized into two major subsets, designated 'classically' or 'alternatively' activated. Classically activated macrophages (cM $\Phi)$ are induced upon stimulation with inflammatory cytokines such as IFN- $\gamma$, IL-12, TNF- $\alpha$ or IL- $1 \beta^{34}$ inducing the expression of inducible nitric oxide synthase (iNOS), which generates nitric oxide (NO). In contrast, alternatively activated macrophages $(\mathrm{a} M \Phi)$ are the product of IL-4, IL-13 and IL-21 signaling 35 inducing the expression of Arginase-1 (Arg-1), Ym-1 and Fizz1 (also known as RELMa). ${ }^{34,36-38}$

Egg deposition in the liver promotes the development of Th2 responses, which in turn increases the number of aaM $\Phi$ in granulomas. ${ }^{39}$ Using several Th1 polarized mice (e.g. IL-10/IL-4 double KO, IL-13/IL-4 double KO or IL-12 and egg immunized ${ }^{38}$ ) or mice conditionally deficient in macrophage specific IL-4 signaling, ${ }^{40}$ infection with $S$. mansoni failed to induce the expression of Arg-1, suggesting a requirement for Th2 cytokines in the development of Arg-1-expressing aaM $\Phi$ 's. Furthermore, Th1-skewed mice displayed enhanced iNOS responses, ${ }^{38}$ which were associated with the formation of smaller granulomas and accelerated mortality, ${ }^{40}$ suggesting the compartmentalization of $\mathrm{cM} \Phi$ with Th1 responses and Arg-1-expressing aaM $\Phi$ with Th2 responses and fibrosis during infection.

L-Arginine, which is transported into macrophages via cationic amino-acid transporters (CAT), is a common substrate for both $\mathrm{cM} \Phi$-associated iNOS and aaMФ-associated Arg-1. As a common denominator, $\mathrm{L}$-arginine has the ability to govern the magnitude of macrophage activity, plasticity of macrophage phenotype and macrophage effector function. ${ }^{41}$ During alternative activation of macrophages, L-arginine is hydrolyzed by Arg and promotes the synthesis of collagen, providing a working model translating Th2 responses into fibrosis during schistosome infections. This view is supported from studies using iNOS-deficient mice, where L-arginine solely drives the differentiation of aaMФs, resulting in significantly increased liver fibrosis and granuloma volume. ${ }^{39}$ Collectively, the differentiation of $\mathrm{CD}^{+} \mathrm{T}$ cells into Th2 effector $\mathrm{T}$ cells and the subsequent downstream polarization of macrophages into an alternatively activated phenotype build a Th2-mediated model of immunopathology during schistosomiasis.

Additional properties of aaMФs, such as the function of Fizz1-expression, are slowly being revealed. It is tempting to speculate from the data so far that this molecule may actually contribute to fibrogenesis. Liu et al. ${ }^{42}$ recently demonstrated that Fizz 1 induces fibroblast differentiation and increases expression of a-smooth muscle actin and type I collagen. Using a model of bleomycin-induced lung fibrosis, in situ hybridization revealed significantly elevated Fizz 1 in fibrotic tissue. Furthermore, Fizz 1 also has antiapoptotic properties and is found in developing tissues ${ }^{43}$ supporting our hypothesis that Fizz 1 in aaMФ's may promote liver fibrosis during infection. However, similar aaM $\Phi$ observed in other helminth infections ${ }^{37,44,45}$ display anti-inflammatory properties, suppressing antigen-specific T-cell proliferation in vitro. ${ }^{46,47}$ Macrophages with suppressive properties have been observed in human $^{48}$ and murine ${ }^{49}$ schistosome infections, where they may also play an immunoregulatory role. As mentioned above, $\mathrm{L}$-arginine is a critical substrate for macrophages and is rapidly consumed by aaM $\Phi$. Starvation of other cells, which also require ${ }_{\mathrm{L}}$-arginine, including $\mathrm{T}$ and $\mathrm{B}$ cells, ${ }^{50}$ may be a mechanism adopted by aaM $\Phi$ to indirectly regulate the activity of other immune cells and reduce inflammation. Macrophages may therefore play a dual role; as an initial inflammatory cell, assisting in sequestering egg products and the development of granulomas; and later adopting an anti-inflammatory role during chronic infection, indirectly suppressing the function of other cells and decreasing the granuloma volume. 


\section{REGULATION OF IL-13-DRIVEN FIBROSIS BY IL-13Ra2}

IL-13 is bound by two distinct receptors; IL-13Ra 1 (which forms a complex with the signaling IL-4Ra chain) and IL-13Ra2. Characteristics of the two receptors, their expression, function and the regulation of IL-13 activity are currently being defined with several recent studies yielding exciting data. IL-13Ra2 was first described as a soluble, high affinity binding protein that inhibits IL-13. ${ }^{51}$ In $S$. mansoni infected mice we have observed a significant increase in IL-13Ra2 in the serum and liver, ${ }^{52,53}$ mirroring the Th2 response against parasite eggs, suggesting that IL-13Ra 2 is driven by $\mathrm{Th} 2$ responses. This hypothesis is supported by data showing the STAT6 dependence of IL-13Ra $2^{52,53}$ and from recent in vitro observations with fibroblasts, which secrete IL-13Ra2 following STAT6 activation.

The upregulation of IL-13Ra2 is critical for controlling IL-13-mediated liver pathology as mice with a targeted deletion of IL-13Ra 2 (IL-13 $\mathrm{Ra}^{-/-}$) develop exacerbated fibrosis compared to infected controls. ${ }^{52,53}$ Furthermore, a soluble IL-13Ra2-Fc construct used to neutralize IL-13 was shown to reverse the excessive liver fibrosis observed in infected $\mathrm{IL}-13 \mathrm{Ra} 2^{-/-}$mice, demonstrating that IL-13Ra2 is functioning as a potent decoy receptor for IL-13 in schistosomiasis. The inhibition of IL-13 by IL-13Ra 2 is not complete; however, as infected Wt mice develop IL-13-dependent liver fibrosis even in the presence of endogenous IL-13Ra2.

Several studies have shown that newly formed liver granulomas surrounding entrapped eggs decrease in size as the infection progresses to the chronic stage. ${ }^{54}$ This 'endogenous desensitization' is a hallmark of the granulomatous response during infection and is thought to be critical for host survival in cases of persistent disease. In addition to controlling IL-13mediated fibrosis; IL-13Ra 2 is required for granuloma downmodulation. S. mansoni infected Wt mice develop large granulomas at 8 weeks post-infection, which begin to decrease in size by week 12 . However, infected IL-13Ra $2^{-/}$mice fail to undergo downmodulation. In fact, their granulomas continue to increase in size as the infection becomes chronic. ${ }^{53}$ This defect in granuloma modulation was associated with markedly increased mortality, suggesting that tight control of IL-13 is required for survival during chronic infections with $S$. mansoni. Understanding how the various IL-13 receptors (positive signaling via IL-4Ra/IL-13Ra1, inhibition by the IL-13Ra2) are regulated will be of great importance for many Th2-associated diseases including asthma ${ }^{55,56}$ ulcerative colitis ${ }^{57}$ and schistosomiasis.

\section{CONTROL OF IMMUNOPATHOLOGY BY REGULATORY LYMPHOCYTES}

So far this review of immunopathology of schistosomiasis has focused on the effector mechanisms that develop during infection with schistosomes. However, from initial exposure to infective cercariae through Th1 and Th2 cell differentiation and ultimately fibrogenesis, every process is tightly controlled and paralleled with an equal regulatory response, constantly recalibrating immune homeostasis. Thus, an efficient and regulated immune response to infectious pathogens must be receptive to external signals, beyond the immune system, to maintain physiological stability. To this end, extraimmunological mechanisms controlling the magnitude of the immune response, such as HPA-axis mediators and hormones, ${ }^{58}$ as well as signals from structural tissue cells, such as kupfer cells and hepatocytes ${ }^{59}$ 'talk' to the immune system and alter the magnitude of the response. Whereas this understudied area of extraimmunological regulation serves an important function, maintaining homeostasis, this section will focus on interimmunological control by professional regulatory cells of the immune system.

Mounting a sufficient effector response against a metabolically active parasite, to reduce parasitic burden, while at the same time limiting collateral damage poses great difficulty for 
the host. Regulatory CD4 ${ }^{+} \mathrm{T}$ cells (Treg) maintain immunological homeostasis, suppressing the activation of autoreactive cells, ${ }^{60}$ as well as controlling the magnitude of immune responses to invading pathogens. ${ }^{61}$ Such endogenous Treg cells have been called 'natural' regulatory cells. In addition, regulatory T cells that respond in parallel with effector mechanisms, termed 'inducible' regulatory cells, also develop to control the magnitude of the immune response. Both natural and inducible Treg's provide essential immunological control to restrict immune-mediated pathology and stabilize the immune system.

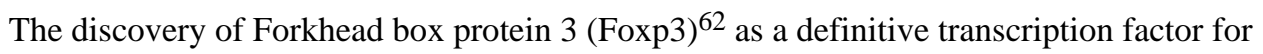
natural Treg cells has allowed investigators to separate natural Treg cells from inducible Treg cells with similar regulatory properties. Foxp $3^{+}$natural regulatory $\mathrm{T}$ cells develop in the thymus and serve as an essential component of the T-cell repertoire in the periphery. Constitutive expression of the a chain of the IL-2 receptor (CD25) ${ }^{63}$ and the requirement for IL-2 (reviewed by Thornton ${ }^{64}$ ) along with potent inhibitory coreceptor expression, CTLA-4, and the glucocorticoid-inducible TNF receptor, GITR, serve as additional markers of natural Treg's and provide clues to their function and mechanism of suppression.

Inducible regulatory $\mathrm{T}$ cells often mirror the proliferation of antigen-driven effector T-cell responses and originate from common conventional $\mathrm{CD}^{+}{ }^{+}$cells. Additionally, inducible Treg cells can be differentiated in vitro with a cocktail of cytokines or drugs. ${ }^{65}$ Current nomenclatures for inducible Treg cells include; IL-10-secreting 'Tr1' cells, TGF- $\beta$-secreting 'Th3' cells and regulatory $\mathrm{CD} 4^{+} \mathrm{CD} 25^{+} \mathrm{Foxp} 3^{-}$cells. Collectively, Treg cells represent a population of professional suppressor cells, with the unique and primary function to suppress immune responses and prevent immune-driven pathology. From the wider immunology field, ${ }^{66,67}$ infectious disease biology ${ }^{61}$ and specifically within schistosome infections ${ }^{68-73}$ Treg's have received a great deal of attention as professional regulatory cells.

Early indications of Treg activity in helminth infections were observed in filarial and schistosome infected patients presenting a hyporesponsive T-cell phenotype.

Responsiveness, however, is recoverable in vitro with antibodies to IL-10 and/or TGF- $\beta$, two cytokines associated with Treg-mediated suppression. ${ }^{74,75}$ Recent studies have confirmed these initial speculations of Treg activity in helminth infections (reviewed by Wilson and Maizels ${ }^{76}$ ). Functional in vivo depletion studies have identified Treg populations in murine filarial ${ }^{77}$ and intestinal nematode infections, ${ }^{78,79}$ with the suggestion that enhanced Treg responses may dampen antihelminth effector responses, allowing the establishment of chronic infections.

During schistosome infections, both natural and inducible Treg cells have been described, with varying roles including the suppression of DC activation, the orchestration of the Th2 response and the regulation of Th2 effector responses, granuloma development and fibrosis. From 4 weeks post-infection with $S$. mansoni a significant expansion of natural Treg cells, $\mathrm{CD} 4^{+} \mathrm{CD} 25^{+} \mathrm{Foxp}^{+}$, develop in the mesenteric lymph nodes with further expansion and accumulation of Tregs in the liver and spleen thereafter (Wilson et al., unpublished observation). ${ }^{70,72}$ Similarly, a single immunization with $S$. mansoni eggs invokes a significant Foxp $3^{+}$Treg response ${ }^{71}$ suggesting that the highly immunogenic egg antigens (SEA) may be the most potent inducer of both effector and Treg cells during infection. However, lysophosphatidylserine (Lyso-PS) extracted from $S$. mansoni worms, and to a lesser degree $S$. mansoni eggs, can actively induce IL-10-secreting Treg cells, via TLR-2 signaling on dendritic cells (DCs), ${ }^{80}$ suggesting that Tregs can be directly induced by parasite-derived molecules. Alternatively, SEA-driven effector T-cell responses may subsequently facilitate a Treg response by stimulating the production of T-cell-derived IL- 2 . Interestingly, the ratio of Treg's: effector T cells, either following infection or egg immunization, does not appear to change, ${ }^{70,71}$ suggesting that the expansion of effector $\mathrm{T}$ 
cells are closely monitored and equaled by a regulatory T-cell response. Whether Treg cells are directly induced by parasites or simply develop in parallel with the effector T-cell response is not yet clear.

Phenotypic studies of Treg's during schistosome infections have identified the expression of $\mathrm{CD} 103$, an aE $\beta 7$ T-cell integrin. ${ }^{70} \mathrm{CD} 103$ provides essential retention properties for lymphocytes, maintaining cell adhesion at basolateral surfaces, assisting cell-to-cell contact and possibly identifying a cell-cell-contact-mediated Treg function. ${ }^{81,82}$ Additionally, CD103 expression has been reported on DCs, attributed with the same function - to retain cell contact - and provide essential assistance for Treg-mediated suppression. ${ }^{82}$ The precise role and requirement of CD103 during $S$. mansoni infection, however, has not yet been clearly elucidated, but it is tempting to speculate that targeting CD103 may dampen Treg cell function and tilt the balance in favor of effector responses. Additionally, neuropilin-1, a receptor involved in axon guidance, angiogenesis, and the activation of T cells, has also been identified on natural Treg cells during $S$. mansoni infection. Originally identified through global gene expression studies, ${ }^{83}$ high expression of surface neuropilin-1 correlated with Foxp3 expression and is rapidly downregulated following T-cell antigen receptor (TCR)-ligation. Again, the role of neuropilin-1 on Treg cells during $S$. mansoni infection is still unknown.

Despite the clear identification of natural Treg cells during infection, exactly how natural Treg cells control immunopathology is less clear. IL-10 has clear regulatory roles during $S$. mansoni infection and critically regulates liver pathology; ${ }^{23,84}$ however, the majority of the IL-10-producing T cells appear to be Foxp3 ${ }^{-}$and thus constitute inducible Treg cells and/or Th2 cells ${ }^{69,70}$ and will be addressed in detail below. To address the functional role of Tregs, several studies have used the CD4 and CD25 surface markers. However, within the $\mathrm{CD} 4^{+} \mathrm{CD} 25^{+}$compartment both natural $\left(\mathrm{Foxp}^{+}\right.$) and inducible (Foxp3 ${ }^{-}$) Treg cells exist, making it hard to attribute function to either Treg population. Nevertheless, using an eggimmunization model coupled with the depletion of $\mathrm{CD} 25^{+}$cells ('natural Treg depleted') to address the role of $\mathrm{CD} 25^{+}$Treg cells, both IFN- $\gamma$ and IL-4 responses were elevated following immunization, indicating that $\mathrm{CD} 25^{+}$Tregs suppress both Th1 and Th2 generation..$^{70,71}$ Furthermore, suppression of IL-4 ${ }^{70,71}$ and IFN- $\gamma^{71}$ appears to be IL-10 independent. An alternative approach to address the role of Foxp $3^{+}$regulatory cells was adopted by Singh et al. ${ }^{72}$ using retroviral Foxp3 gene transfer. Intravenous delivery of a DNA vector for Foxp3 between week 6 and 8 of infection with $S$. mansoni (during the development of granulomas in the liver) significantly reduced liver granuloma volumes from $142.88 \pm 4.97 \times 10^{3}$ to $75.79 \pm 2.84 \times 10^{3} \mu \mathrm{m}^{2}$. However, correlating with enhanced Foxp3 expression and reduced granuloma volume was an increase in messenger (m) RNA for TGF$\beta$, IL-4 and IFN- $\gamma$, complicating interpretation of this strategy of artificially induced Foxp3 ${ }^{+}$ Treg cells. The advent of Foxp $3^{+}$reporter mice, containing the Foxp3 green fluorescent protein (gfp) knock-in allele, ${ }^{85}$ will now permit detailed analysis, sorting and definitive adoptive transfer experiments to study the development, function and specificity of natural Treg cells in $S$. mansoni infection.

In addition to natural Treg cells, significant populations of inducible Treg's, $\mathrm{CD} 4^{+} \mathrm{CD} 25^{+} \mathrm{Foxp}^{-}$, develop following infection with $S$. mansoni. ${ }^{68,69,73}$ As mentioned above, the majority of IL-10-producing $\mathrm{CD}^{+} \mathrm{T}$ cells, also coexpress $\mathrm{CD} 25$ and do not upregulate the natural Treg transcription factor Foxp3. Using RAG2 KO and IL-10 ${ }^{-/-}$ RAG2 KO mice reconstituted with Wt or IL- $10^{-/-} \mathrm{CD} 4^{+}$cells, controlling the source of IL-10, Hesse et al. ${ }^{68}$ elegantly demonstrated that $\mathrm{CD} 4^{+}$cells provide a significant proportion of IL-10 during S. mansoni infection. Importantly, non-CD4-derived IL-10 is also an important source of IL-10. Similarly, McKee and Pearce ${ }^{69}$ reported that IL-10 from $\mathrm{CD} 4{ }^{+} \mathrm{CD} 25^{+}$, and $\mathrm{CD} 4{ }^{+} \mathrm{CD} 25^{-}$cells, is important for the control of DC-derived IL-12 and 
the generation of Th1 responses during infection, helping to mold the T-cell response into a Th2 phenotype. Thus, it appears that both natural and inducible Treg cells have the capacity to control both Th1 ${ }^{69}$ and Th $2^{70}$ development.

IL-10-secreting $\mathrm{CD} 4{ }^{+} \mathrm{CD} 25^{+}$cells isolated from the granuloma of chronically infected mice 68,69 can suppress the proliferation of naïve $\mathrm{CD} 4^{+} \mathrm{T}$ cells. Thus, unlike natural Treg cells in $v_{i v o}{ }^{70}$ which do not appear to regulate the proliferation of T cells, inducible Treg cells can suppress the proliferation of effector $\mathrm{T}$ cells in vitro, providing an interesting disparity between these two populations. Further work is required to clarify this observation in parallel experiments, in vitro and in vivo.

The accumulation and suppressive properties of $\mathrm{CD} 4{ }^{+} \mathrm{CD} 25^{+}$cells isolated from the liver of infected mice suggests that Treg cells actively migrate to the inflammatory site to regulate the development of liver granulomas during infection. Studies addressing the trafficking of Treg's using SEA-coated sepharose beads delivered to the lungs of mice, have revealed the elevated expression of CCR $8^{73}$ (a chemokine receptor initially described on Th2 cells), on IL-10-secreting $\mathrm{CD} 4{ }^{+} \mathrm{CD} 25^{+}$cells, providing an essential mechanism to recruit Treg's into the inflammatory site.

Finally, to investigate the requirement and importance of Treg cells during schistosomiasis, adoptive transfer of CD25-depleted CD4 $4^{+}$cells ('natural and inducible Treg depleted') into RAG KO mice, resulted in increased weight loss, elevated hepatotoxicity and increased mortality following infection, ${ }^{68}$ demonstrating a requirement for Tregs to control liver pathology. In addition to the Treg-mediated suppression of T-cell function and proliferation in schistosome infections, Treg cells may influence the function of macrophages, ${ }^{86} \mathrm{CD} 8^{+}$ cells, ${ }^{87} \mathrm{~B}$ cells ${ }^{88}$ and eosinophil recruitment. ${ }^{78}$ Each of these cell types contribute to liver granuloma formation and may be controlled by regulatory $\mathrm{T}$ cells, although the upstream suppression of Th2 cytokine secretion and effector function appear to be the major targets of Tregs.

The importance of Treg cells to control immunopathology following infection with schistosomes are clear, with recent advancements providing specific mechanistic roles for Treg cells. However, many questions remain pertaining to the generation, function, tropism and specificity of Treg cells and the relationship, if any, between natural and inducible Tregs. Several scenarios could be proposed; (1) natural Treg cells give rise to inducible Treg cells following antigen activation with the loss of Foxp3 expression within inducible Treg populations - this could explain the relatively low frequency of natural Treg's. This scenario would also provide suitable antigen-specificity, appropriate tropism and paracrine cytokine 'tutoring'. In addition, this would give natural Tregs the ability to control the frequency of inducible Tregs; (2) natural Treg cells may expand following cues form effector T cells, such as IL-2, with the expansion of natural (Foxp $3^{+}$) and inducible Treg cells in concert with clonally expanding Ag-specific cells; (3) inducible Treg cells may develop from mature effector $\mathrm{CD} 4^{+} \mathrm{T}$ cells, serving as the terminus of the Th1 or Th2 lineages. Again, this scenario would provide antigen-specificity and appropriate tropism. Alternatively, natural and inducible regulatory T-cell populations may not evolve with any common ancestry and simply converge to control inflammatory events. The precise mechanism of Treg-mediated suppression during schistosome infection in vivo, beyond IL-10 secretion, remains elusive, with current studies revealing new and exciting mechanisms and networks.

\section{CONCLUSION}

Immunopathology presented in schistosomiasis, like filariasis, is some of the worst, and unacceptable, of any infectious pathogen. Foremost, there is sufficient knowledge to treat or 
prevent infection, which will hopefully eradicate these and other treatable waterborne parasitic infections. ${ }^{7}$ The morbidity associated with schistosomiasis impacts multiple layers of society, from direct individual health to local community education and economy. ${ }^{89}$ The immunology of schistosomiasis is also faced with challenges with no current vaccine available and insufficient knowledge of dominant antigens for future vaccine targets. Furthermore, our current knowledge is insufficient to restrain granuloma-associated immunopathology. Treg-associated suppression has received a lot of attention as a dominant regulatory system and promises to be an exciting field of immunobiology over the next few years. However, a broader view of immune regulation and an appreciation of interactive networks within and beyond the immune system require a 'voice', if we are to develop successful immunotherapies for schistosomiasis. To this end, understanding when and how endogenous regulatory networks operate to control immunopathology could be very useful to limit the degree of immunopathology of not only schistosomiasis, but also for other Th2dominated diseases such as asthma and allergic diseases.

\section{References}

1. Pearce EJ, MacDonald AS. The immunobiology of schistosomiasis. Nat Rev Immunol. 2002; 2:499-511. [PubMed: 12094224]

2. Wynn TA, Thompson RW, Cheever AW, Mentink-Kane MM. Immunopathogenesis of schistosomiasis. Immunol Rev. 2004; 201:156-167. [PubMed: 15361239]

3. Damian RT, Roberts ML, Powell MR, Clark JD, Lewis FA, Stirewalt MA. Schistosoma mansoni egg granuloma size reduction in challenged baboons after vaccination with irradiated cryopreserved schistosomula. Proc Natl Acad Sci USA. 1984; 81:3552-3556. [PubMed: 6587370]

4. Schistosomiasis Control'. Report of a WHO Expert Committee. WHO Tech Rep Ser. 1973; 515:147.

5. Steinmann P, Keiser J, Bos R, Tanner M, Utzinger J. Schistosomiasis and water resources development: systematic review, meta-analysis, and estimates of people at risk. Lancet Infect Dis. 2006; 6:411-425. [PubMed: 16790382]

6. Garba A, Toure S, Dembele R, Bosque-Oliva E, Fenwick A. Implementation of national schistosomiasis control programmes in West Africa. Trends Parasitol. 2006; 22:322-326. [PubMed: 16690357]

7. Fenwick A. Waterborne infectious diseases - could they be consigned to history? Science. 2006; 313:1077-1081. [PubMed: 16931751]

8. Dessein A, Kouriba B, Eboumbou C, Dessein H, Argiro L, Marquet S, et al. Interleukin--13 in the skin and interferon-gamma in the liver are key players in immune protection in human schistosomiasis. Immunol Rev. 2004; 201:180-190. [PubMed: 15361241]

9. Secor WE. Immunology of human schistosomiasis: off the beaten path. Parasite Immunol. 2005; 27:309-316. [PubMed: 16138852]

10. Vennervald BJ, Dunne DW. Morbidity in schistosomiasis: an update. Curr Opin Infect Dis. 2004; 17:439-447. [PubMed: 15353964]

11. Abath FG, Morais CN, Montenegro CE, Wynn TA, Montenegro SM. Immunopathogenic mechanisms in schistosomiasis: what can be learnt from human studies? Trends Parasitol. 2006; 22:85-91. [PubMed: 16380294]

12. Phillips SM, DiConza JJ, Gold JA, Reid WA. Schistosomiasis in the congenitally athymic (nude) mouse. I. Thymic dependency of eosinophilia, granuloma formation, and host morbidity. J Immunol. 1977; 118:594-599. [PubMed: 839071]

13. Hsu CK, Hsu SH, Whitney RA Jr, Hansen CT. Immunopathology of schistosomiasis in athymic mice. Nature. 1976; 262:397-399. [PubMed: 1085416]

14. Mathew RC, Boros DL. Anti-L3T4 antibody treatment suppresses hepatic granuloma formation and abrogates antigen-induced interleukin-2 production in Schistosoma mansoni infection. Infect Immun. 1986; 54:820-826. [PubMed: 3096893] 
15. Cheever AW, Williams ME, Wynn TA, Finkelman FD, Seder RA, Cox TM. Anti-IL-4 treatment of Schistosoma mansoni-infected mice inhibits development of T cells and non-B, non-T cells expressing Th2 cytokines while decreasing egg-induced hepatic fibrosis. J Immunol. 1994; 153:753-759. [PubMed: 8021510]

16. Reiman RM, Thompson RW, Feng CG, Hari D, Knight R, Cheever AW, et al. Interleukin-5 (IL-5) augments the progression of liver fibrosis by regulating IL-13 activity. Infect Immun. 2006; 74:1471-1479. [PubMed: 16495517]

17. Kaviratne M, Hesse M, Leusink M, Cheever AW, Davies SJ, McKerrow JH, et al. IL-13 activates a mechanism of tissue fibrosis that is completely TGF- $\{$ beta $\}$ independent. J Immunol. 2004; 173:4020-4029. [PubMed: 15356151]

18. Wynn TA, Cheever AW, Jankovic D, Poindexter RW, Caspar P, Lewis FA, et al. An IL-12-based vaccination method for preventing fibrosis induced by schistosome infection. Nature. 1995; 376:594-596. [PubMed: 7637808]

19. Jankovic D, Kullberg MC, Noben-Trauth N, Caspar P, Ward JM, Cheever AW, et al. Schistosomeinfected IL-4 receptor knockout (KO) mice, in contrast to IL-4 KO mice, fail to develop granulomatous pathology while maintaining the same lymphokine expression profile. J Immunol. 1999; 163:337-342. [PubMed: 10384133]

20. Kaplan MH, Whitfield JR, Boros DL, Grusby MJ. Th2 cells are required for the Schistosoma mansoni egg-induced granulomatous response. J Immunol. 1998; 160:1850-1856. [PubMed: 9469446]

21. Rezende SA, Oliveira VR, Silva AM, Alves JB, Goes AM, Reis LF. Mice lacking the gamma interferon receptor have an impaired granulomatous reaction to Schistosoma mansoni infection. Infect Immun. 1997; 65:3457-3461. [PubMed: 9234812]

22. Mukai T, Nagaki M, Imose M, Kimura K, Satake S, Takai S, et al. Prevention of hepatic fibrosis in nonobese diabetic mice: a critical role for interferon-gamma. Liver Int. 2006; 26:1006-1014. [PubMed: 16953842]

23. Hoffmann KF, Cheever AW, Wynn TA. IL-10 and the dangers of immune polarization: excessive type 1 and type 2 cytokine responses induce distinct forms of lethal immunopathology in murine schistosomiasis. J Immunol. 2000; 164:6406-6416. [PubMed: 10843696]

24. Harrington LE, Hatton RD, Mangan PR, Turner H, Murphy TL, Murphy KM, et al. Interleukin 17producing CD4+ effector T cells develop via a lineage distinct from the Thelper type 1 and 2 lineages. Nat Immunol. 2005; 6:1123-1132. [PubMed: 16200070]

25. Park H, Li Z, Yang XO, Chang SH, Nurieva R, Wang YH, et al. A distinct lineage of CD4T cells regulates tissue inflammation by producing interleukin 17. Nat Immunol. 2005; 6:1133-1141. [PubMed: 16200068]

26. Cruz A, Khader SA, Torrado E, Fraga A, Pearl JE, Pedrosa J, et al. Cutting edge: IFN-gamma regulates the induction and expansion of IL-17-producing CD4T cells during mycobacterial infection. J Immunol. 2006; 177:1416-1420. [PubMed: 16849446]

27. Lubberts E, Joosten LA, Chabaud M, van Den Bersselaar L, Oppers B, Coenen-De Roo CJ, et al. IL-4 gene therapy for collagen arthritis suppresses synovial IL-17 and osteoprotegerin ligand and prevents bone erosion. J Clin Invest. 2000; 105:1697-1710. [PubMed: 10862785]

28. Rutitzky LI, Hernandez HJ, Stadecker MJ. Th1-polarizing immunization with egg antigens correlates with severe exacerbation of immunopathology and death in schistosome infection. Proc Natl Acad Sci USA. 2001; 98:13243-13248. [PubMed: 11606762]

29. Rutitzky LI, Lopes da Rosa JR, Stadecker MJ. Severe CD4T cell-mediated immunopathology in murine schistosomiasis is dependent on IL-12p40 and correlates with high levels of IL-17. J Immunol. 2005; 175:3920-3926. [PubMed: 16148138]

30. Booth M, Mwatha JK, Joseph S, Jones FM, Kadzo H, Ireri E, et al. Periportal fibrosis in human Schistosoma mansoni infection is associated with low IL-10, low IFN-gamma, high TNF-alpha, or low RANTES, depending on age and gender. J Immunol. 2004; 172:1295-1303. [PubMed: 14707108]

31. Henri S, Chevillard C, Mergani A, Paris P, Gaudart J, Camilla C, et al. Cytokine regulation of periportal fibrosis in humans infected with Schistosoma mansoni: IFN-gamma is associated with 
protection against fibrosis and TNF-alpha with aggravation of disease. J Immunol. 2002; 169:929936. [PubMed: 12097398]

32. de Jesus AR, Magalhaes A, Miranda DG, Miranda RG, Araujo MI, de Jesus AA, et al. Association of type 2 cytokines with hepatic fibrosis in human Schistosoma mansoni infection. Infect Immun. 2004; 72:3391-3397. [PubMed: 15155645]

33. Alves Oliveira LF, Moreno EC, Gazzinelli G, Martins-Filho OA, Silveira AM, Gazzinelli A, et al. Cytokine production associated with periportal fibrosis during chronic Schistosomiasis mansoni in humans. Infect Immun. 2006; 74:1215-1221. [PubMed: 16428771]

34. Gordon S. Alternative activation of macrophages. Nat Rev Immunol. 2003; 3:23-35. [PubMed: 12511873]

35. Pesce J, Kaviratne M, Ramalingam TR, Thompson RW, Urban JF Jr, Cheever AW, et al. The IL-21 receptor augments Th2 effector function and alternative macrophage activation. J Clin Invest. 2006; 116:2044-2055. [PubMed: 16778988]

36. Welch JS, Escoubet-Lozach L, Sykes DB, Liddiard K, Greaves DR, Glass CK. TH2 cytokines and allergic challenge induce Ym1 expression in macrophages by a STAT6-dependent mechanism. $\mathrm{J}$ Biol Chem. 2002; 277:42821-42829. [PubMed: 12215441]

37. Loke P, Nair MG, Parkinson J, Guiliano D, Blaxter M, Allen JE. IL-4 dependent alternativelyactivated macrophages have a distinctive in vivo gene expression phenotype. BMC Immunol. 2002; 3:7. [PubMed: 12098359]

38. Hesse M, Modolell M, La Flamme AC, Schito M, Fuentes JM, Cheever AW, et al. Differential regulation of nitric oxide synthase- 2 and arginase- 1 by type 1/type 2 cytokines in vivo: granulomatous pathology is shaped by the pattern of 1-arginine metabolism. J Immunol. 2001; 167:6533-6544. [PubMed: 11714822]

39. Hesse M, Cheever AW, Jankovic D, Wynn TA. NOS-2 mediates the protective anti-inflammatory and antifibrotic effects of the Th1-inducing adjuvant, IL-12, in a Th2 model of granulomatous disease. Am J Pathol. 2000; 157:945-955. [PubMed: 10980133]

40. Herbert DR, Holscher C, Mohrs M, Arendse B, Schwegmann A, Radwanska M, et al. Alternative macrophage activation is essential for survival during schistosomiasis and downmodulates $\mathrm{T}$ helper 1 responses and immunopathology. Immunity. 2004; 20:623-635. [PubMed: 15142530]

41. Rutschman R, Lang R, Hesse M, Ihle JN, Wynn TA, Murray PJ. Cutting edge: Stat6-dependent substrate depletion regulates nitric oxide production. J Immunol. 2001; 166:2173-2177. [PubMed: 11160269]

42. Liu T, Dhanasekaran SM, Jin H, Hu B, Tomlins SA, Chinnaiyan AM, et al. FIZZ1 stimulation of myofibroblast differentiation. Am J Pathol. 2004; 164:1315-1326. [PubMed: 15039219]

43. Wagner KF, Hellberg AK, Balenger S, Depping R, Dodd OJ, Johns RA, et al. Hypoxiainduced mitogenic factor has antiapoptotic action and is upregulated in the developing lung: coexpression with hypoxia-inducible factor-2alpha. Am J Respir Cell Mol Biol. 2004; 31:276-282. [PubMed: 15117738]

44. Rodriguez-Sosa M, Satoskar AR, Calderon R, Gomez-Garcia L, Saavedra R, Bojalil R, et al. Chronic helminth infection induces alternatively activated macrophages expressing high levels of CCR5 with low interleukin-12 production and Th2-biasing ability. Infect Immun. 2002; 70:36563664. [PubMed: 12065507]

45. Piessens WF, Ratiwayanto S, Tuti S, Palmieri JH, Piessens PW, Koiman I, et al. Antigen-specific suppressor cells and suppressor factors in human filariasis with Brugia malayi. N Engl J Med. 1980; 302:833-837. [PubMed: 6444695]

46. Taylor MD, Harris A, Nair MG, Maizels RM, Allen JE. F4/80+ alternatively activated macrophages control CD4+ T cell hyporesponsiveness at sites peripheral to filarial infection. $\mathrm{J}$ Immunol. 2006; 176:6918-6927. [PubMed: 16709852]

47. Loke P, MacDonald AS, Robb A, Maizels RM, Allen JE. Alternatively activated macrophages induced by nematode infection inhibit proliferation via cell-to-cell contact. Eur J Immunol. 2000; 30:2669-2678. [PubMed: 11009101]

48. Todd CW, Goodgame RW, Colley DG. Immune responses during human Schistosomiasis mansoni.V. Suppression of schistosome antigen-specific lymphocyte blastogenesis by adherent/ phagocytic cells. J Immunol. 1979; 122:1440-1446. [PubMed: 87433] 
49. Flores Villanueva PO, Harris TS, Ricklan DE, Stadecker MJ. Macrophages from schistosomal egg granulomas induce unresponsiveness in specific cloned Th-1 lymphocytes in vitro and downregulate schistosomal granulomatous disease in vivo. J Immunol. 1994; 152:1847-1855. [PubMed: 8120394]

50. Bronte V, Serafini P, Mazzoni A, Segal DM, Zanovello P. 1-Arginine metabolism in myeloid cells controls T-lymphocyte functions. Trends Immunol. 2003; 24:302-306. [PubMed: 12810105]

51. Zhang JG, Hilton DJ, Willson TA, McFarlane C, Roberts BA, Moritz RL, et al. Identification, purification, and characterization of a soluble interleukin (IL)-13-binding protein. Evidence that it is distinct from the cloned Il-13 receptor and Il-4 receptor alpha-chains. J Biol Chem. 1997; 272:9474-9480. [PubMed: 9083087]

52. Chiaramonte MG, Mentink-Kane M, Jacobson BA, Cheever AW, Whitters MJ, Goad ME, et al. Regulation and function of the interleukin 13 receptor alpha 2 during a T helper cell type 2dominant immune response. J Exp Med. 2003; 197:687-701. [PubMed: 12642601]

53. Mentink-Kane MM, Cheever AW, Thompson RW, Hari DM, Kabatereine NB, Vennervald BJ, et al. IL-13 receptor alpha 2 down-modulates granulomatous inflammation and prolongs host survival in schistosomiasis. Proc Natl Acad Sci USA. 2004; 101:586-590. [PubMed: 14699044]

54. Domingo EO, Warren KS. Endogenous desensitization: changing host granulomatou response to schistosome eggs at different stages of infection with Schistosoma mansoni. Am J Pathol. 1968; 52:369-379. [PubMed: 5635858]

55. Grunig G, Warnock M, Wakil AE, Venkayya R, Brombacher F, Rennick DM, et al. Requirement for IL-13 independently of IL-4 in experimental asthma. Science. 1998; 282:2261-2263. [PubMed: 9856950]

56. Wills-Karp M, Luyimbazi J, Xu X, Schofield B, Neben TY, Karp CL, et al. Interleukin-13: central mediator of allergic asthma. Science. 1998; 282:2258-2261. [PubMed: 9856949]

57. Heller F, Florian P, Bojarski C, Richter J, Christ M, Hillenbrand B, et al. Interleukin-13 is the key effector Th2 cytokine in ulcerative colitis that affects epithelial tight junctions, apoptosis, and cell restitution. Gastroenterology. 2005; 129:550-564. [PubMed: 16083712]

58. Brewer JA, Kanagawa O, Sleckman BP, Muglia LJ. Thymocyte apoptosis induced by T cell activation is mediated by glucocorticoids in vivo. J Immunol. 2002; 169:1837-1843. [PubMed: 12165507]

59. Rutella S, Bonanno G, Procoli A, Mariotti A, de Ritis DG, Curti A, et al. Hepatocyte growth factor favors monocyte differentiation into regulatory interleukin (IL)-10++IL-12low/neg accessory cells with dendritic-cell features. Blood. 2006; 108:218-227. [PubMed: 16527888]

60. Sakaguchi S, Ono M, Setoguchi R, Yagi H, Hori S, Fehervari Z, et al. Foxp3CD25CD4 natural regulatory $\mathrm{T}$ cells in dominant self-tolerance and autoimmune disease. Immunol Rev. 2006; 212:8-27. [PubMed: 16903903]

61. Belkaid Y, Rouse BT. Natural regulatory T cells in infectious disease. Nat Immunol. 2005; 6:353360. [PubMed: 15785761]

62. Fontenot JD, Gavin MA, Rudensky AY. Foxp3 programs the development and function of CD4+CD25+ regulatory T cells. Nat Immunol. 2003; 4:330-336. [PubMed: 12612578]

63. Sakaguchi S, Sakaguchi N, Asano M, Itoh M, Toda M. Immunologic self-tolerance maintained by activated T cells expressing IL-2 receptor alpha-chains (CD25). Breakdown of a single mechanism of self-tolerance causes various autoimmune diseases. J Immunol. 1995; 155:1151-1164. [PubMed: 7636184]

64. Thornton AM. Signal transduction in CD4+CD25+ regulatory T cells: CD25 and IL-2. Front Biosci. 2006; 11:921-927. [PubMed: 16146782]

65. Barrat FJ, Cua DJ, Boonstra A, Richards DF, Crain C, Savelkoul HF, et al. In vitro generation of interleukin 10-producing regulatory CD4(+) $\mathrm{T}$ cells is induced by immunosuppressive drugs and inhibited by T helper type 1 (Th1)- and Th2-inducing cytokines. J Exp Med. 2002; 195:603-616. [PubMed: 11877483]

66. Sakaguchi S. Naturally arising Foxp3-expressing CD25+CD4+ regulatory T cells in immunological tolerance to self and non-self. Nat Immunol. 2005; 6:345-352. [PubMed: 15785760] 
67. Shevach EM. CD4+ CD25+ suppressor T cells: more questions than answers. Nat Rev Immunol. 2002; 2:389-400. [PubMed: 12093005]

68. Hesse M, Piccirillo CA, Belkaid Y, Prufer J, Mentink-Kane M, Leusink M, et al. The pathogenesis of schistosomiasis is controlled by cooperating IL-10-producing innate effector and regulatory $\mathrm{T}$ cells. J Immunol. 2004; 172:3157-3166. [PubMed: 14978122]

69. McKee AS, Pearce EJ. CD25+CD4+ cells contribute to Th2 polarization during helminth infection by suppressing Th1 response development. J Immunol. 2004; 173:1224-1231. [PubMed: 15240714]

70. Baumgart M, Tompkins F, Leng J, Hesse M. Naturally occurring CD4+Foxp3+ regulatory T cells are an essential, IL-10-independent part of the immunoregulatory network in Schistosoma mansoni egg-induced inflammation. J Immunol. 2006; 176:5374-5387. [PubMed: 16622005]

71. Taylor JJ, Mohrs M, Pearce EJ. Regulatory T cell responses develop in parallel to Th responses and control the magnitude and phenotype of the Th effector population. J Immunol. 2006; 176:5839-5847. [PubMed: 16670290]

72. Singh KP, Gerard HC, Hudson AP, Reddy TR, Boros DL. Retroviral Foxp3 gene transfer ameliorates liver granuloma pathology in Schistosoma mansoni infected mice. Immunology. 2005; 114:410-417. [PubMed: 15720442]

73. Freeman CM, Chiu BC, Stolberg VR, Hu J, Zeibecoglou K, Lukacs NW, et al. CCR8 is expressed by antigen-elicited, IL-10-producing CD4+CD25+ T cells, which regulate Th2-mediated granuloma formation in mice. J Immunol. 2005; 174:1962-1970. [PubMed: 15699124]

74. Doetze A, Satoguina J, Burchard G, Rau T, Loliger C, Fleischer B, et al. Antigen-specific cellular hyporesponsiveness in a chronic human helminth infection is mediated by $T(h) 3 / T(r) 1-t y p e$ cytokines IL-10 and transforming growth factor-beta but not by a T(h)1 to T(h)2 shift. Int Immunol. 2000; 12:623-630. [PubMed: 10784608]

75. Hoerauf A, Brattig N. Resistance and susceptibility in human onchocerciasis — beyond Th1 vs Th2. Trends Parasitol. 2002; 18:25-31. [PubMed: 11850011]

76. Wilson MS, Maizels RM. Regulatory T cells induced by parasites and the modulation of allergic responses. Chem Immunol Allergy. 2006; 90:176-195. [PubMed: 16210910]

77. Taylor MD, LeGoff L, Harris A, Malone E, Allen JE, Maizels RM. Removal of regulatory T cell activity reverses hyporesponsiveness and leads to filarial parasite clearance in vivo. J Immunol. 2005; 174:4924-4933. [PubMed: 15814720]

78. Wilson MS, Taylor MD, Balic A, Finney CA, Lamb JR, Maizels RM. Suppression of allergic airway inflammation by helminth-induced regulatory T cells. J Exp Med. 2005; 202:1199-1212. [PubMed: 16275759]

79. Elliott DE, Setiawan T, Metwali A, Blum A, Urban JF Jr, Weinstock JV. Heligmosomoides polygyrus inhibits established colitis in IL-10-deficient mice. Eur J Immunol. 2004; 34:2690. [PubMed: 15368285]

80. van der Kleij D, Latz E, Brouwers JF, Kruize YC, Schmitz M, Kurt-Jones EA, et al. A novel hostparasite lipid cross-talk. Schistosomal lyso-phosphatidylserine activates toll-like receptor 2 and affects immune polarization. J Biol Chem. 2002; 277:48122-48129. [PubMed: 12359728]

81. Leithauser F, Meinhardt-Krajina T, Fink K, Wotschke B, Moller P, Reimann J. Foxp3-expressing $\mathrm{CD} 103+$ regulatory $\mathrm{T}$ cells accumulate in dendritic cell aggregates of the colonic mucosa in murine transfer colitis. Am J Pathol. 2006; 168:1898-1909. [PubMed: 16723705]

82. Annacker O, Coombes JL, Malmstrom V, Uhlig HH, Bourne T, Johansson-Lindbom B, et al. Essential role for CD103 in the T cell-mediated regulation of experimental colitis. J Exp Med. 2005; 202:1051-1061. [PubMed: 16216886]

83. Bruder D, Probst-Kepper M, Westendorf AM, Geffers R, Beissert S, Loser K, et al. Neuropilin-1: a surface marker of regulatory T cells. Eur J Immunol. 2004; 34:623-630. [PubMed: 14991591]

84. Wynn TA, Cheever AW, Williams ME, Hieny S, Caspar P, Kuhn R, et al. IL-10 regulates liver pathology in acute murine Schistosomiasis mansoni but is not required for immune downmodulation of chronic disease. J Immunol. 1998; 160:4473-4480. [PubMed: 9574553]

85. Wan YY, Flavell RA. Identifying Foxp3-expressing suppressor T cells with a bicistronic reporter. Proc Natl Acad Sci USA. 2005; 102:5126-5131. [PubMed: 15795373] 
86. Taams LS, van Amelsfort JM, Tiemessen MM, Jacobs KM, de Jong EC, Akbar AN, et al. Modulation of monocyte/macrophage function by human CD4+CD25+ regulatory T cells. Hum Immunol. 2005; 66:222-230. [PubMed: 15784460]

87. Robertson SJ, Messer RJ, Carmody AB, Hasenkrug KJ. In vitro suppression of CD8+ T cell function by Friend virus-induced regulatory T cells. J Immunol. 2006; 176:3342-3349. [PubMed: 16517701]

88. Lim HW, Hillsamer P, Banham AH, Kim CH. Cutting edge: direct suppression of B cells by CD4+ CD25+ regulatory T cells. J Immunol. 2005; 175:4180-4183. [PubMed: 16177055]

89. King CH, Dickman K, Tisch DJ. Reassessment of the cost of chronic helmintic infection: a metaanalysis of disability-related outcomes in endemic schistosomiasis. Lancet. 2005; 365:1561-1569. [PubMed: 15866310] 